American Journal of Applied Sciences 6 (3): 401-406, 2009

ISSN 1546-9239

(C) 2009 Science Publications

\title{
Comparison of UPFC-Based Stabilizer and PSS Performances on Damping of Power System Oscillations
}

\author{
${ }^{1}$ M.R. Meshkatoddini, ${ }^{2}$ M. Majidi, ${ }^{3}$ M. Sadeghierad and ${ }^{4}$ H. Lesani \\ ${ }^{1,2}$ Shahid Abbaspour PWUT University of Technology, Tehran, Iran \\ ${ }^{3,4}$ Faculty of Elec. and Computer Engineering, University of Tehran, Iran
}

\begin{abstract}
This paper establishes the linearized Phillips-Heffron model of a power system equipped with UPFC and demonstrates the application of the model in analyzing the damping effect of the UPFC and designing UPFC based stabilizer to improve power system oscillation stability. A comprehensive approach to the design of UPFC based stabilizer (power flow control, DC-voltage regulator and damping controller) is presented. In this case, the multi-machine power system with UPFC is studied and an example of power system is presented. It is shown that the DC voltage contributes negative damping to power system oscillations, which is confirmed by both eigenvalue computation and nonlinear simulation. To counterattack the negative damping effect due to the DC voltage regulator, UPFC based stabilizer is designed and its effectiveness is demonstrated by both eigenvalue computation and nonlinear simulation. Then the effects of UPFC and PSS on power systems are compared. Simulation results show that the performance of UPFC based stabilizer on damping of power system is better than PSS.
\end{abstract}

Key words: Phillips-heffron model, UPFC, stabilizer, PSS

\section{INTRODUCTION}

The Unified Power Flow Controller (UPFC) is a FACTS device which can control power system parameters such as terminal voltage, line impedance and phase angle ${ }^{[1-2]}$. The primary function of the UPFC is to control power flow on a given and voltage at the UPFC bus. This is achieved by regulating the controllable parameters of the systems, line impedance, phase angle and voltage magnitude. The UPFC can also be utilized for damping power system oscillations by judiciously applying damping controller. For a UPFC based stabilizer, we wish to extract an input signal for damping controller from the locally measurable quantities at the UPFC location. The electrical power flow can be easily measured at the UPFC location and hence may be used as an input signal for the damping controller.

Steady state and dynamic models of UPFC have been developed by several researchers ${ }^{[3-5]} \cdot \mathrm{In}^{[6]}$, unified Phillips-Heffron model of a power system is established for several types of FACTS devices installed in the system.

This research establishes the linearized PhillipsHeffron model of a power system equipped with UPFC and demonstrates the application of the model in analyzing the damping effect of the UPFC and also designing UPFC based stabilizer to improve power system oscillation stability. A comprehensive approach to the design of UPFC based stabilizer (power flow control, DC-voltage regulator and damping controller) is presented.

In this case, the multi-machine power system with UPFC is studied and an example of power systems is presented. It has been shown that the DC voltage contributes negative damping to power system oscillations, which is confirmed by both eigenvalue computation and nonlinear simulation. To counterattack the negative damping effect due to the DC voltage regulator, UPFC based stabilizer is designed and its effectiveness is demonstrated by both eigenvalue computation and nonlinear simulation. Then we compare the effect of UPFC and PSS on power systems.

\section{MATERIALS AND METHODS}

The UPFC is a device designed for the real-time control and dynamic compensation of $\mathrm{AC}$ transmission system, providing the multifunctional flexibility required to solve many of the problems facing the power supply industry. The UPFC is a combination of a

Corresponding Author: Mohammad R. Meshkatoddini, Shahid Abbaspour PWUT University of Technology, P.O. Box 167651719, Tehran, Iran Tel: +98-912-1329464 Fax: +98-21-77310425 


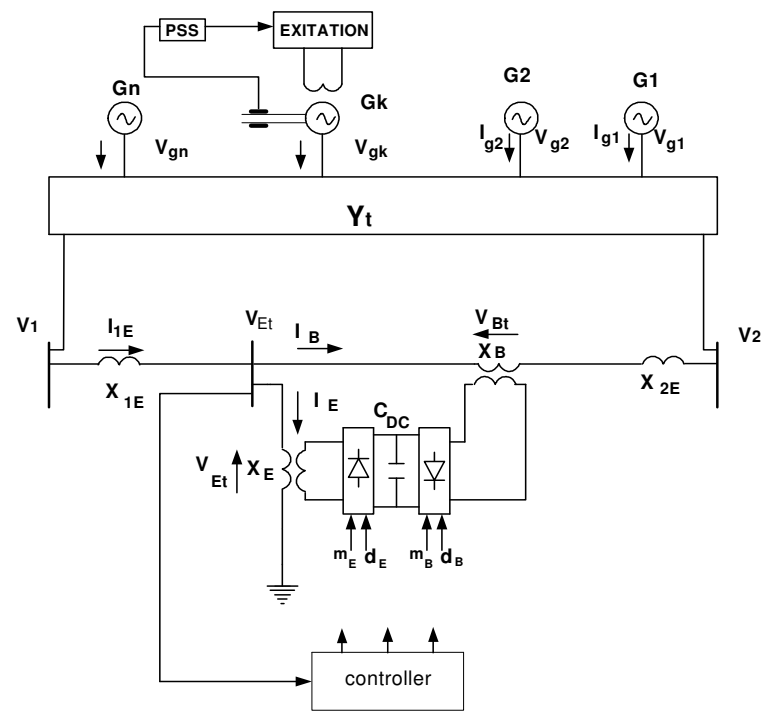

Fig. 1: n-machine power system with UPFC

STATic synchronous COMpensator (STATCOM) and a Static Synchronous Series compensator (SSSC) which is established via a common DC voltage link. It is capable of controlling, simultaneously or selectively, all the parameters affecting the power flow in a transmission line (voltage, impedance and phase angle). Alternatively it can control both the real and reactive power flows in the line independently ${ }^{[1,7]}$. The UPFC may also provide an independent, controllable, shunt reactive compensation.

Without loss of generality, assume that a UPFC is to be installed in an n-machine power system between node 1 and 2 as shown by Fig. 1. The UPFC consists of an Excitation Transformer (ET), a Boosting Transformer (BT), a pair of three-phase GTO based Voltage Source Converters (VSCs) and a DC link capacitor. In Fig. $1, \mathrm{~m}_{\mathrm{E}}, \mathrm{m}_{\mathrm{B}}$ and $\delta_{\mathrm{E}}, \delta_{\mathrm{B}}$ are the amplitude modulation ratio and phase angles of the control signals to the $\mathrm{UPFC}^{[6]}$.

\section{DYNAMIC MODEL OF THE MULTI-MACHINE POWER SYSTEM WITH UPFC}

Non-linear dynamic model: A nonlinear dynamic model of the system is derived by disregarding the resistances of the system components (generator, transformer, transmission lines, shunt and series converter transformers) and the transients of the transmission lines and transformer of the UPFC. The nonlinear dynamic model of the system using UPFC is given below.

It can also be assumed that, before the UPFC is installed in the power system, the network admittance matrix $\bar{Y}_{t}$ is formed whereonly $n$ generator nodes plus node 1 and 2 are kept. By the installation of the UPFC between node 1 and 2, the circuit equations of the network are as fellow:

$$
\begin{aligned}
& \overline{\mathrm{Y}}_{11}^{\prime} \overline{\mathrm{V}}_{1}+\overline{\mathrm{I}}_{1 \mathrm{E}}+\overline{\mathrm{Y}}_{13} \overline{\mathrm{V}}_{\mathrm{g}}=0 \\
& \overline{\mathrm{Y}}^{\prime}{ }_{22} \overline{\mathrm{V}}_{2}+\overline{\mathrm{I}}_{\mathrm{E} 2}+\overline{\mathrm{Y}}_{23} \overline{\mathrm{V}}_{\mathrm{g}}=0 \\
& \overline{\mathrm{Y}}_{31} \overline{\mathrm{V}}_{1}+\overline{\mathrm{Y}}_{32} \overline{\mathrm{V}}_{2}+\overline{\mathrm{Y}}_{33} \overline{\mathrm{V}}_{\mathrm{g}}=\overline{\mathrm{I}}_{\mathrm{g}}
\end{aligned}
$$

where

$$
\mathrm{I}_{\mathrm{g}}=\left[\mathrm{I}_{\mathrm{g} 1} \mathrm{I}_{\mathrm{g} 2} \ldots . \mathrm{I}_{\mathrm{gn}}\right]^{\mathrm{T}}, \overline{\mathrm{V}}_{\mathrm{g}}=\left[\mathrm{V}_{\mathrm{g} 1} \mathrm{~V}_{\mathrm{g} 2} \ldots . \mathrm{V}_{\mathrm{gn}}\right]^{\mathrm{T}}
$$

${\overline{Y^{\prime}}}_{11}$ and ${\overline{Y^{\prime}}}_{22}$ are obtained from $\overline{\mathrm{Y}}_{11}$ and $\overline{\mathrm{Y}}_{22}$ by excluding $\mathrm{x}_{12}=\mathrm{x}_{1 \mathrm{E}}+\mathrm{x}_{\mathrm{E} 2}$, from Fig. 1 .

$$
\begin{aligned}
& \overline{\mathrm{V}}_{1}=\mathrm{jx}_{\mathrm{IE}} \overline{\mathrm{I}}_{\mathrm{IE}}+\overline{\mathrm{V}}_{\mathrm{Et}} \\
& \overline{\mathrm{V}}_{\mathrm{Et}}=\mathrm{jx}_{\mathrm{E} 2} \overline{\mathrm{I}}_{\mathrm{E} 2}+\overline{\mathrm{V}}_{\mathrm{Et}}+\overline{\mathrm{V}}_{2} \\
& \overline{\mathrm{I}}_{\mathrm{E}}=\overline{\mathrm{I}}_{\mathrm{IE}}-\overline{\mathrm{I}}_{\mathrm{E} 2} \\
& {\left[\begin{array}{l}
\overline{\mathrm{I}}_{1 \mathrm{E}} \\
\overline{\mathrm{I}}_{2 \mathrm{E}}
\end{array}\right]=\frac{1}{\mathrm{x} \sum}\left[\begin{array}{cc}
-\mathrm{j}\left(\mathrm{x}_{\mathrm{E}}+\mathrm{x}_{\mathrm{E} 2}+\mathrm{x}_{\mathrm{B}}\right) & \mathrm{jx_{ \textrm {E } }} \\
-\mathrm{jx}_{\mathrm{E}} & \mathrm{j}\left(\mathrm{x}_{1 \mathrm{E}}+\mathrm{x}_{\mathrm{E}}\right)
\end{array}\right]\left[\begin{array}{c}
\overline{\mathrm{V}}_{1} \\
\overline{\mathrm{V}}_{2}
\end{array}\right]} \\
& +\frac{1}{x \sum}\left[\begin{array}{rc}
j\left(x_{E 2}+x_{B}\right) & j x_{E} \\
-j x_{E} & j\left(x_{1 E}+x_{E}\right)
\end{array}\right]\left[\begin{array}{c}
\bar{V}_{E} \\
\bar{V}_{B}
\end{array}\right]
\end{aligned}
$$

where

$$
\mathrm{x}_{\Sigma}=\left(\mathrm{x}_{1 \mathrm{E}}+\mathrm{x}_{\mathrm{E}}\right)\left(\mathrm{x}_{\mathrm{E}}+\mathrm{x}_{2 \mathrm{E}}+\mathrm{x}_{\mathrm{B}}\right)-\mathrm{x}_{\mathrm{E}}^{2}
$$

By substituting Eq. 1 in Eq. 2:

$$
\overline{\mathrm{I}}_{\mathrm{g}}=\overline{\mathrm{C}}_{\mathrm{g}}+\overline{\mathrm{F}}_{\mathrm{E}} \overline{\mathrm{V}}_{\mathrm{E}}+\overline{\mathrm{F}}_{\mathrm{B}} \overline{\mathrm{V}}_{\mathrm{B}}
$$

where:

$$
\begin{aligned}
& \overline{\mathrm{C}}=\overline{\mathrm{Y}}_{33}-\left[\overline{\mathrm{Y}}_{31} \overline{\mathrm{Y}}_{31}\right] \overline{\mathrm{Y}}_{\mathrm{t}}^{-1}\left[\begin{array}{l}
\overline{\mathrm{Y}}_{13} \\
\overline{\mathrm{Y}}_{23}
\end{array}\right] \\
& \overline{\mathrm{F}}_{\mathrm{E}}=-\left[\overline{\mathrm{Y}}_{31} \overline{\mathrm{Y}}_{31}\right]{\overline{\mathrm{Y}^{\prime}}}_{\mathrm{t}}^{-1}\left[\begin{array}{l}
\frac{\mathrm{j}\left(\mathrm{x}_{\mathrm{E} 2}+\mathrm{x}_{\mathrm{B}}\right)}{\mathrm{x}_{\Sigma}} \\
\frac{\mathrm{j} \mathrm{x}_{\mathrm{E} 1}}{\mathrm{x}_{\Sigma}}
\end{array}\right] \\
& \overline{\mathrm{F}}_{\mathrm{B}}=-\left[\overline{\mathrm{Y}}_{31} \overline{\mathrm{Y}}_{31}\right]{\overline{\mathrm{Y}^{\prime}}}_{\mathrm{t}}^{-1}\left[\begin{array}{l}
\frac{\mathrm{j} \mathrm{x}_{\mathrm{E}}}{\mathrm{x}_{\Sigma}} \\
\frac{-\mathrm{j}\left(\mathrm{x}_{1 \mathrm{E}}+\mathrm{x}_{\mathrm{E}}\right)}{\mathrm{x}_{\Sigma}}
\end{array}\right]
\end{aligned}
$$




$$
\bar{Y}_{\mathrm{t}}^{\prime}=\left[\begin{array}{cc}
{\overline{Y^{\prime}}}_{11}-\frac{j\left(x_{E}+x_{E 2}+x_{B}\right)}{x_{\Sigma}} & \frac{j x_{E}}{x_{\Sigma}} \\
\frac{j x_{E}}{x_{\Sigma}} & \overline{Y_{22}^{\prime}}-\frac{j\left(x_{1 E}+x_{E}\right)}{x_{\Sigma}}
\end{array}\right]
$$

The expression of Eq. 4 in terms of $\mathrm{d}-\mathrm{q}$ coordination:

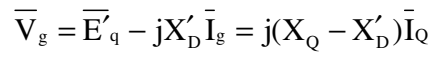

$$
\begin{aligned}
& \mathrm{I}_{\mathrm{g}}= \\
& \overline{\mathrm{C}}_{\mathrm{d}}\left[{\overline{\mathrm{E}^{\prime}}}_{\mathrm{q}}-\mathrm{j}\left(\mathrm{X}_{\mathrm{Q}}-\mathrm{X}_{\mathrm{D}}^{\prime}\right) \overline{\mathrm{I}}_{\mathrm{Q}}+\overline{\mathrm{C}}_{\mathrm{E}} \overline{\mathrm{V}}_{\mathrm{E}}+\overline{\mathrm{C}}_{\mathrm{B}} \overline{\mathrm{V}}_{\mathrm{B}}\right] \\
& \overline{\mathrm{C}}_{\mathrm{d}}=\left(\overline{\mathrm{C}}^{-1}+\mathrm{j} \mathrm{X}_{\mathrm{D}}^{\prime}\right)^{-1} \\
& \overline{\mathrm{C}}_{\mathrm{E}}=\overline{\mathrm{C}}^{-1} \overline{\mathrm{F}}_{\mathrm{E}} \\
& \overline{\mathrm{C}}_{\mathrm{B}}=\overline{\mathrm{C}}^{-1} \overline{\mathrm{F}}_{\mathrm{B}} \\
& \overline{\mathrm{I}}_{\mathrm{Gi}}=\overline{\bar{I}}_{\mathrm{gi}} \mathrm{e}^{\mathrm{j} \delta_{\mathrm{i}}} \\
& =\sum_{\mathrm{k}=1}^{\mathrm{n}} \overline{\mathrm{C}}_{\mathrm{dik}}\left[\begin{array}{l}
\mathrm{E}_{\mathrm{qk}}^{\prime} \mathrm{e}^{\mathrm{j}\left(90^{\circ}+\delta_{\mathrm{k}}-\delta_{\mathrm{i}}\right)}+\left(\mathrm{x}_{\mathrm{qk}}-\mathrm{x}_{\mathrm{dk}}^{\prime}\right) \mathrm{e}^{\mathrm{j}\left(\delta_{\mathrm{k}}-\delta_{\mathrm{i}}\right)} \mathrm{I}_{\mathrm{qk}} \\
+\overline{\mathrm{C}}_{\mathrm{Ek}} \overline{\mathrm{V}}_{\mathrm{E}} \mathrm{e}^{\mathrm{j} \delta_{\mathrm{i}}}+\overline{\mathrm{C}}_{\mathrm{Bk}} \overline{\mathrm{V}}_{\mathrm{B}} \mathrm{e}^{\mathrm{j} \mathrm{\delta}_{\mathrm{i}}}
\end{array}\right] \\
& \mathrm{I}_{\mathrm{di}}=\sum_{\mathrm{k}=1}^{\mathrm{n}} \mathrm{C}_{\mathrm{dik}}\left\{\begin{array}{l}
-\mathrm{E}_{\mathrm{gk}}^{\prime} \sin \delta_{\mathrm{ikg}}+\left(\mathrm{x}_{\mathrm{qk}}-\mathrm{x}_{\mathrm{dk}}^{\prime}\right) \mathrm{I}_{\mathrm{qk}} \cos \delta_{\mathrm{ikg}} \\
+\mathrm{C}_{\mathrm{Ek}} \mathrm{V}_{\mathrm{E}} \cos \delta_{\mathrm{Ek}}+\mathrm{C}_{\mathrm{Bk}} \mathrm{V}_{\mathrm{B}} \cos \delta_{\mathrm{Bk}}
\end{array}\right\} \\
& \mathrm{I}_{\mathrm{qi}}=\sum_{\mathrm{k}=1}^{\mathrm{n}} \mathrm{C}_{\mathrm{dik}}\left\{\begin{array}{l}
\mathrm{E}_{\mathrm{gk}}^{\prime} \cos \delta_{\mathrm{ikg}}+\left(\mathrm{x}_{\mathrm{qk}}-\mathrm{x}_{\mathrm{dk}}^{\prime}\right) \mathrm{I}_{\mathrm{qk}} \cos \delta_{\mathrm{ikg}} \\
+\mathrm{C}_{\mathrm{Ek}} \mathrm{V}_{\mathrm{E}} \sin \delta_{\mathrm{Ek}}+\mathrm{C}_{\mathrm{Bk}} \mathrm{V}_{\mathrm{B}} \sin \delta_{\mathrm{Bk}}
\end{array}\right\}
\end{aligned}
$$

Modified phillips-heffron model of a multimachine power system including UPFC: The linearized model of power system has been successfully adopted for the analysis of power systems oscillation stability and design of power system damping controllers. The linearized model of $\mathrm{n}$-machine power system installed with UPFC can be obtained by linearizing Eq. 1 and 7 around an operating point of power system. This will produce a generic linearized model of the power system oscillation stability, a simplified model of generators can be used by neglecting the internal resistance and sub-transient period of the generators.

By linearizing the equation 7 we will have:

$$
\begin{aligned}
& \Delta \mathrm{I}_{\mathrm{q}}=\mathrm{Y}_{\mathrm{q}} \Delta \delta+\mathrm{F}_{\mathrm{q}} \Delta \mathrm{E}_{\mathrm{q}}^{\prime}+\mathrm{G}_{\mathrm{q}} \Delta \mathrm{V}_{\mathrm{DC}} \\
& +\mathrm{H}_{\mathrm{Eq}} \Delta \mathrm{m}_{\mathrm{E}}+\mathrm{H}_{\mathrm{Bq}} \Delta \delta_{\mathrm{E}}+\mathrm{R}_{\mathrm{Eq}} \Delta \mathrm{m}_{\mathrm{B}}+\mathrm{R}_{\mathrm{Bq}} \Delta \delta_{\mathrm{B}} \\
& \Delta \mathrm{I}_{\mathrm{d}}=\mathrm{Y}_{\mathrm{d}} \Delta \delta+\mathrm{F}_{\mathrm{d}} \Delta \mathrm{E}_{\mathrm{d}}^{\prime}+\mathrm{G}_{\mathrm{d}} \Delta \mathrm{V}_{\mathrm{DC}} \\
& +\mathrm{H}_{\mathrm{Ed}} \Delta \mathrm{m}_{\mathrm{E}}+\mathrm{H}_{\mathrm{Bd}} \Delta \delta_{\mathrm{E}}+\mathrm{R}_{\mathrm{Ed}} \Delta \mathrm{m}_{\mathrm{B}}+\mathrm{R}_{\mathrm{Bd}} \Delta \delta_{\mathrm{B}}
\end{aligned}
$$

Substituting Eq. 8 into the linearized equation of the n-machine power system, we can obtain the

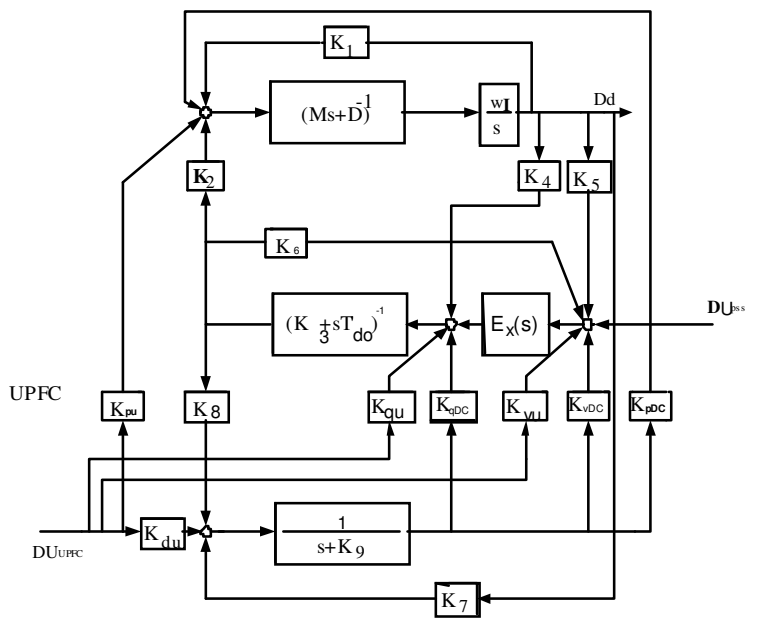

Fig. 2: Modified heffron-phillips model of multimachine power system with UPFC

modified Phillips-Heffron model of multimachine power system with UPFC.

Dynamic in state-space form: The dynamic model of the system in state-space form is obtained from the transfer function model as:

$$
\begin{aligned}
& \dot{X}=A X+B u
\end{aligned}
$$

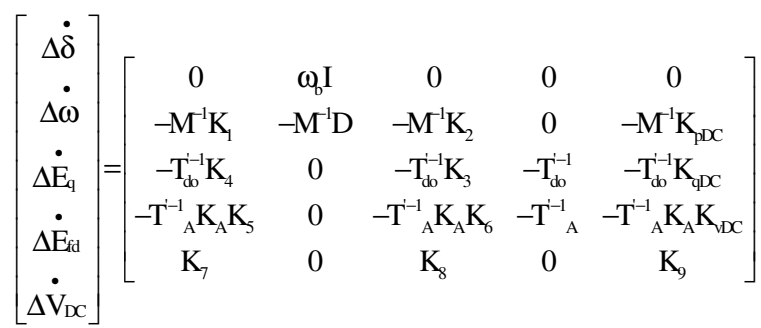

$$
\begin{aligned}
& {\left[\begin{array}{c}
\Delta \delta \\
\Delta \omega \\
\Delta \mathrm{E}_{\mathrm{q}}^{\prime} \\
\Delta \mathrm{E}_{\mathrm{Fd}} \\
\Delta \mathrm{V}_{\mathrm{DC}}
\end{array}\right]+\left[\begin{array}{c}
0 \\
-\mathrm{M}^{-1} \mathrm{~K}_{\mathrm{p}} \mathrm{I}_{\mathrm{n}} \\
-\mathrm{T}^{-1}{ }_{\mathrm{d}} \mathrm{K}_{\mathrm{q}} \mathrm{I}_{\mathrm{n}} \\
-\mathrm{T}^{-1}{ }_{\mathrm{A}} \mathrm{K}_{\mathrm{A}} \mathrm{K}_{\mathrm{u}} \mathrm{I}_{\mathrm{n}} \\
\mathrm{K}_{\mathrm{c}} \mathrm{I}_{\mathrm{n}}
\end{array}\right] \times \Delta \mathrm{U}_{\mathrm{LPF}}+\left[\begin{array}{r}
0 \\
0 \\
0 \\
-\mathrm{K}_{\mathrm{A}} \mathrm{T}^{-1} \mathrm{~A}_{\mathrm{A}} \\
0
\end{array}\right] \times \Delta \mathrm{U}_{\mathrm{PSS}}}
\end{aligned}
$$

UPFC controllers: The UPFC control system comprises four controllers ${ }^{[7-9]}$ :

- DC voltage regulator,

- AC voltage regulator,

- Power-flow controller,

- Power-system oscillation-damping controllers. 
DC voltage regulator: DC voltage regulator controls DC voltage across the DC capacitor of the UPFC. The DC voltage regulator functions by exchanging active power between the UPFC and the power system. Hence its influence on power system oscillation damping should be expected and can be investigated based on the Phillips-Heffron model.

AC voltage regulator: It was decided to support UPFC bus voltage $\mathrm{V}_{\mathrm{E}}$ on one of the two transmission lines connecting nodes 1 and $3^{[6]}$.

Power flow controller: The UPFC is installed in an nmachine power system between node 1 and node $2^{[6,7]}$.

Power system oscillation damping controller: A damping controller is provided to improve the damping of power system oscillation. The damping controller may be considered as comparing two cascade connected blocks.

\section{Case Study}

we consider a three machine power system with UPFC shown in Fig. 3, parameters of which are given below.

Generators:

$\mathrm{H}_{1}=\mathrm{H}_{2}=20 \mathrm{~s}, \mathrm{H}_{3}=11.8 \mathrm{~s}$,

$\mathrm{D}_{1}=0.0, \mathrm{D}_{2}=0.0, \mathrm{D}_{3}=0.0$,

$\mathrm{T}_{\text {do1 }}^{\prime}=7.5 \mathrm{~s}, \mathrm{~T}_{\mathrm{do} 2}^{\prime}=7.5 \mathrm{~s}, \mathrm{~T}_{\mathrm{do} 3}^{\prime}=4.7 \mathrm{~s}$,

$\mathrm{x}_{\mathrm{d} 1}=0.19, \mathrm{x}_{\mathrm{d} 2}=0.19, \mathrm{x}_{\mathrm{d} 3}=0.41$,

$\mathrm{x}_{\mathrm{q} 1}=0.163, \mathrm{x}_{\mathrm{q} 2}=0.163, \mathrm{x}_{\mathrm{q} 3}=0.33$,

$\mathrm{x}_{\mathrm{d} 1}^{\prime}=0.0765, \mathrm{x}_{\mathrm{d} 2}^{\prime}=0.0765, \mathrm{x}_{\mathrm{d} 3}^{\prime}=0.173$

Excitation:

$\mathrm{K}_{\mathrm{A} 1}=\mathrm{K}_{\mathrm{A} 3}=20, \mathrm{~K}_{\mathrm{A} 2}=100$

$\mathrm{T}_{\mathrm{A} 1}=\mathrm{T}_{\mathrm{A} 3}=0.05 \mathrm{~s}, \mathrm{~T}_{\mathrm{A} 2}=0.01 \mathrm{~s}$

Network and UPFC:

$\mathrm{Z}_{13}=\mathrm{j} 1.2, \mathrm{Z}_{23}=\mathrm{j} 0.2, \mathrm{Z}_{1 \mathrm{E}}=\mathrm{j} 0.2, \mathrm{Z}_{\mathrm{E} 3}=\mathrm{j} 0.2$,

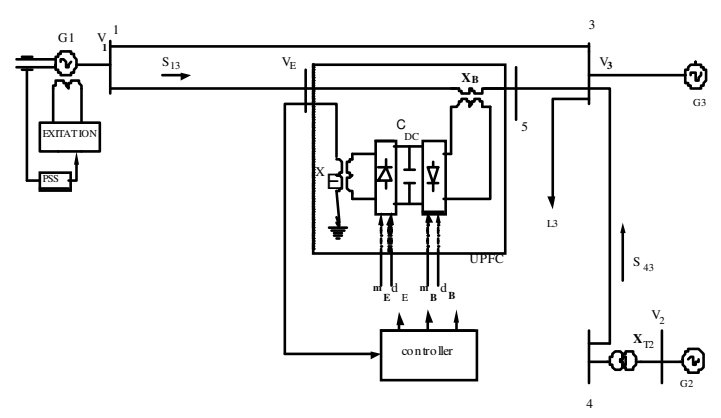

Fig. 3: Example of three machine power system
$\mathrm{L}_{3}=1.5+\mathrm{j} 0.5$

$\mathrm{Z}_{\mathrm{T} 2}=\mathrm{j} 0.03$,

$\mathrm{P}_{53}=0.6$ p.u., $\mathrm{P}_{43}=0.8$ p.u.

$\mathrm{C}_{\mathrm{DC}}=1.0, \mathrm{~V}_{\mathrm{DC} 0}=1.0, \mathrm{~K}_{\mathrm{P}}=10.0, \mathrm{~K}_{\mathrm{V}}=40$

\section{RESULTS AND DISCUSSION}

Table 1 gives the results of computing the oscillation modes of power system from the system linearized model in investing the impact UPFC control on system oscillation stability. We can see that:

- The influence on system oscillation stability of power flow control and voltage control of the UPFC is small (compare the result in the third and fourth rows in Table 1); it can be seen that the UPFC power flow and voltage control have a little effect on the damping of system oscillation modes.

- The addition of the basic voltage control of the DC link capacitor in the UPFC interacts with the PSS on G1, which was designed to damp the inter-area oscillation mode, because the inter-area oscillation occurs again after the installation of the UPFC. The results in the last row of table1 demonstrate the sharp reduction of the damping of the inter-area oscillation mode.

In Table 1 the result in the third row was obtained without UPFC DC capacitor voltage control. This is just a demonstrative case to show that the UPFC power flow and voltage control have no effect on system oscillation stability. In practice these two functions must be applied at the same time as that of UPFC DC capacitor voltage control.

Figure 4-9 compare the effect of UPFC and PSS on power system. Simulation results show that the performance of UPFC based stabilizer on damping of power system is better than PSS.

Figure 5 presents the nonlinear simulation based on the system dynamic model of equations 1 and 7 . The oscillation is triggered by a three-phase short circuit occurring on the transmission line between nodes 3 and 5 in example power system at 1.0 second of the simulation and cleared after $100 \mathrm{~ms}$. It obviously confirms the results in Table 1, the influence of the DC capacitor voltage control is great.

Measures therefore are needed to tackle the interarea oscillation. One option is simply to readjust parameters of the PSS on G1. By adjusting the parameters of the PSS, the inter-area oscillation mode is moved to $-0.440 \pm j 3.810$ and the oscillation will be damped again as confirmed by the non-linear simulation of Fig.6. 
Table1: Results of computing oscillation modes

\begin{tabular}{llc} 
Case study & Local oscillation mode & Inter-area Oscillation mode \\
\hline Three machine without stabilizer & $-1.099 \pm \mathrm{j} 5.500$ & $-0.001 \pm \mathrm{j} 4.400$ \\
PSS on G1 installed & $-1.380 \pm \mathrm{j} 5.600$ & $-0.495 \pm \mathrm{j} 4.310$ \\
UPFC installed with power flow and voltage control function and PSS on G1 installed & $-1.001 \pm \mathrm{j} 5.610$ & $-0.490 \pm \mathrm{j} 4.300$ \\
UPFC installed with power flow, voltage control function, UPFC DC voltage control & $-1.001 \pm \mathrm{j} 5.630$ & $-0.110 \pm \mathrm{j} 3.910$ \\
function and PSS installed on G1 & & \\
\hline
\end{tabular}

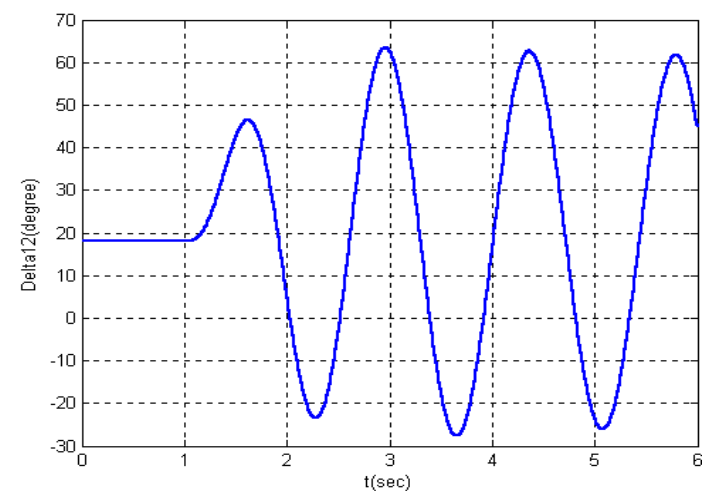

Fig. 4: Whithout stabilizer

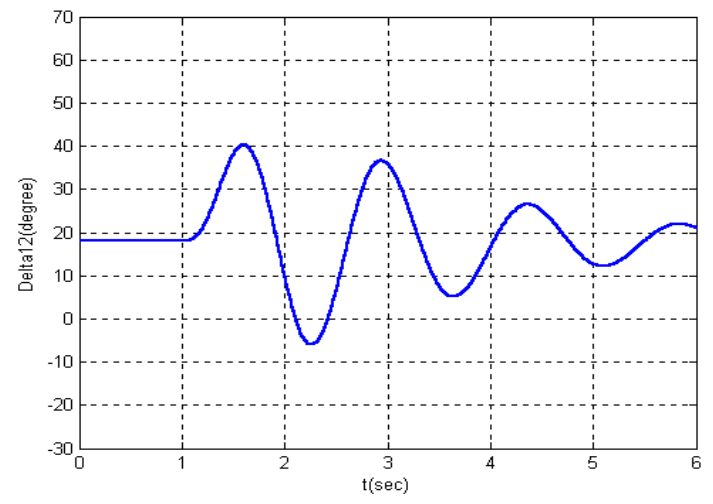

Fig. 5: PSS on G1 installed

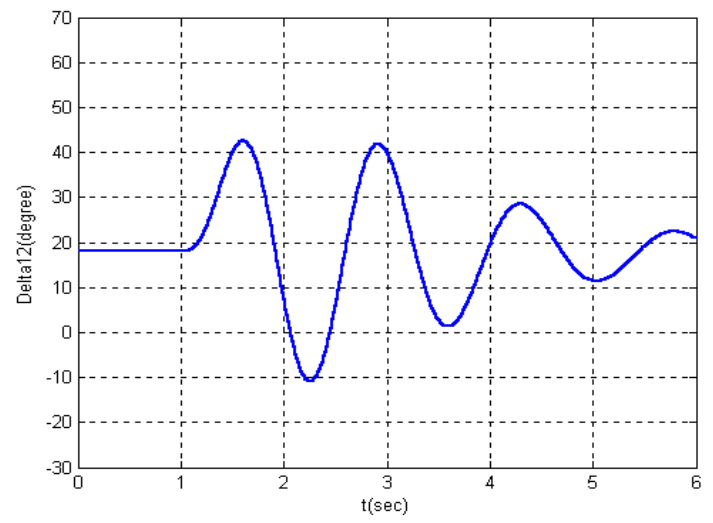

Fig. 6: UPFC installed with power flow and voltage control function and PSS on G1 installed

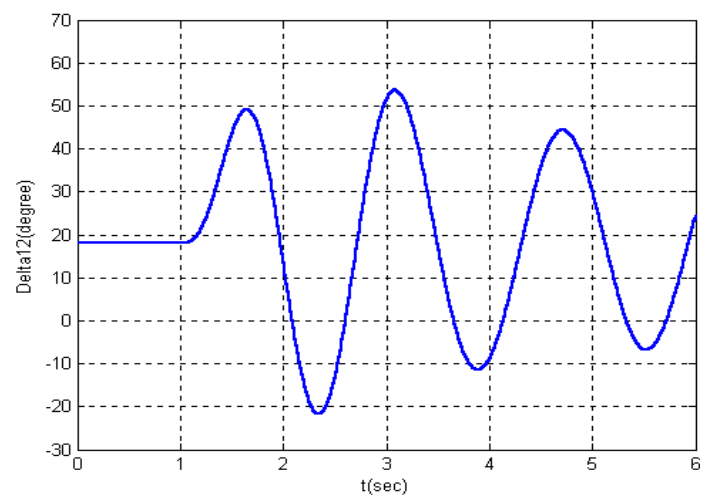

Fig. 7: UPFC installed with power flow, voltage control function, UPFC DC voltage control function and PSS installed on G1

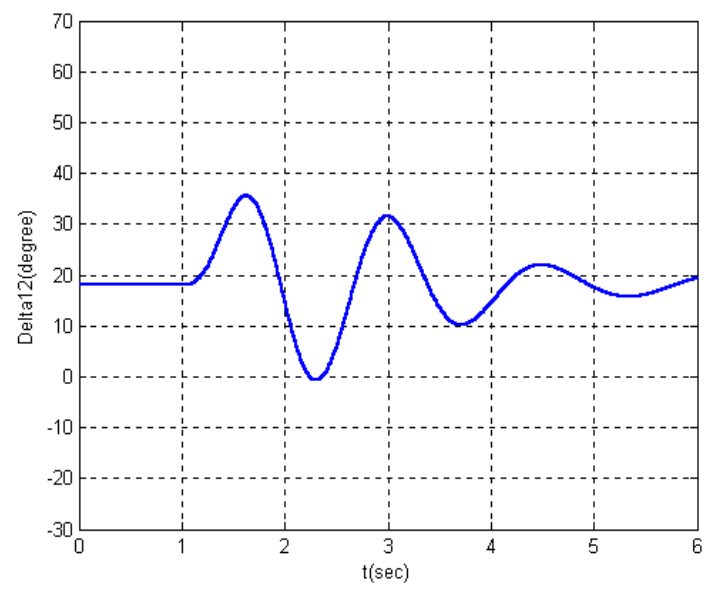

Fig. 8: UPFC installed with power flow, voltage control function, UPFC DC voltage control function and UPFC based stabilizer

Another measure is to introduce damping controller into the UPFC and the feedback signal of the damping controller, $\mathrm{y}_{\mathrm{c}}$, is taken to be the active power delivered along the transmission line from node 3 to node 4. By using the eigenvalue assignment method, the parameters of damping controller are set.

The inter-area oscillation modes are assigned to $-0.590 \pm \mathrm{j} 4.001$ and oscillation is well suppressed as shown by the nonlinear simulation at Fig. 8. 


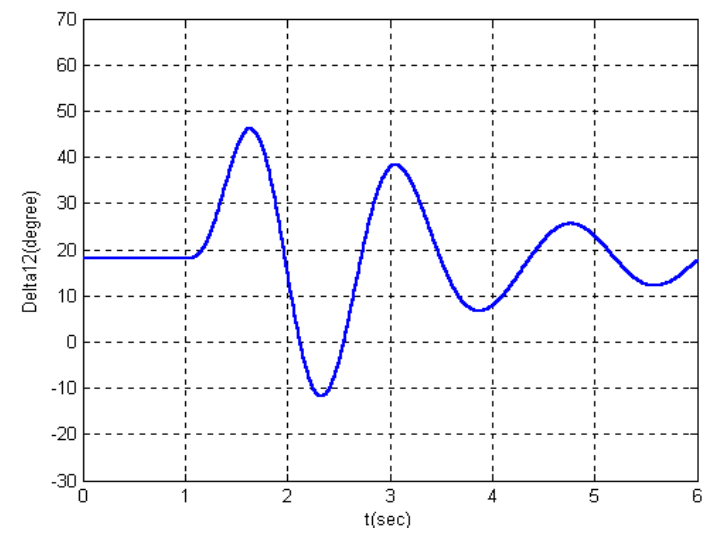

Fig. 9: UPFC installd with power flow, voltage control function, UPFC DC voltage control function and Readjusting PSS installed on G1

\section{CONCLUSION}

This paper established the linearized Heffron-Phillips model of a power system equipped with UPFC and demonstrated the application of the model in analyzing the damping effect of the UPFC. UPFC-based stabilizer was designed to improve power system oscillation stability. The multi-machine power system with UPFC was studied and an example was presented. It was shown that the DC voltage contributes negative damping to power system oscillations, which was confirmed by both eigenvalue computation and nonlinear simulation. The effects of UPFC and PSS on power systems were compared. Simulation results demonstrated that the performance of UPFC-based stabilizer on damping of power system oscillations is better than PSS.

\section{REFERENCES}

1. Gyugyi, L., C.D. Schauder, S.L. Williams, T.R. Rietman, D.R. Torgerson, A. Edris, 1995. The unified power flow controller: A new approach to power transmission control. IEEE Trans. Power Delivery. 10: 1085-1097. Doi: 10.1109/61.400878
2. Nabavi Niaki, S.A., M. Reza Iravani, 2002. Application of unified power flow controller (UPFC) for damping interarea oscillations. Transmission and Distribution Conference and Exhibition 2002: Asia Pacific. IEEE/PES, 6-10 Oct. 1: 348-353. Doi: 10.1109/TDC.2002. 1178360

3. Arabi, S., P. Kundur, 1996. A versatile FACTS device model for powerflow and stability simulations. IEEE Trans. Power Syst., 11: 19441950. Doi: $10.1109 / 59.544668$

4. Noroozian, M. and G. Adersson, 1994. Damping of power system oscillations by use of controllable components. IEEE Trans. Power Delivery, 9: 20462054. Doi: $10.1109 / 61.329537$

5. Heffron, W.G., R.A. Phillips, 1952. Effect of a modern amplidyne voltage regulator on underexcited operation of large turbine generators. Trans. Am. Institute Electrical Eng. Power Apparatus Syst., 71: 692-697. Doi: 10.1109/AIEEPAS.1952.4498530

6. Wang, H.F. and F.J. Swift, 1997. A unified model for the analysis of FACTS devices in damping power system oscillations. I. Singlemachine infinite-bus power systems. IEEE Trans. Power Delivery, 12: 941-946. Doi: 10.1109/61.584417

7. Papic, I., P. Zunko, D. Povh, M. Weinhold, 1997. Basic control of unified power flow controller. IEEE Trans. Power Syst., 12: 1734-1739. Doi: $10.1109 / 59.627884$

8. Schoder, K., A. Hasanovic and A. Feliachi, 2001. Power system damping using fuzzy controlled unified power flow controller. IEEE Power Engineering Society Winter Meeting, 28 Jan.1 Feb. 2: 617-622. Doi: 10.1109/PESW.2001. 916920

9. Liming Liu, Pengcheng Zhu, Yong Kang and Jian Chen, 2007. Power-flow control performance analysis of a unified power-flow controller in a novel control scheme. IEEE Trans. Power Delivery, 22: 1613-1619. Doi: 10.1109/TPWRD.2006.886799 